\title{
Bootstrapping microcomputers at Drexel University: The role of a faculty newsletter
}

\author{
THOMAS T. HEWETT and DONALD J. PERKEY \\ Drexel University, Philadelphia, Pennsylvania
}

\begin{abstract}
Drexel University requires entering freshmen to have access to a personal microcomputer. Part of the faculty development effort was a faculty newsletter, boot. The newsletter published information about microcomputers and their applications and about microcomputer-related events on campus. Unlike newsletters produced by academic computing centers, boot was edited by faculty, most of its pieces were written by faculty, and it was addressed to all members of the university community, not just that subgroup with a prior interest in, or prior record of, computer use. This article describes the publication and presents data indicating that the faculty found it to be clearly worthwhile.
\end{abstract}

In the fall of 1982, the president of Drexel University, William W. Hagerty, announced that the university would require all incoming freshmen, from academic year 19831984 onward, to have access to a personal microcomputer. Following this announcement, the vice president for academic affairs, Bernard Sagik, formed two faculty committees to oversee and aid in implementing the new policy; the two committees were the Microcomputer Selection Committee and the Microcomputer Users' Implementation Committee. The work of the Selection Committee was completed during the fall 1982 term with the submission of a final report (Smith et al., 1984) and the recommendation of Apple Computer Corporation's Macintosh computer. The Users' Committee continued to meet and work on problems associated with the integration of the microcomputer into Drexel's education program through the summer of 1984.

In addition, a variety of activities were initiated which focused on preparation of faculty. Once the decision to require personal computers for incoming freshmen had been made, the university needed a large-scale, ongoing program for faculty and staff development. This program had to be relevant both to the operation of personal computers and to their integration into the educational process. Therefore, the university's model of what constitutes "development" included much more than just training in how to use microcomputers. One component of the faculty development effort was a microcomputer newsletter, boot.

\footnotetext{
The publication of boot was made possible by a grant to Drexel University from the Pew Memorial Trust. The authors would like to express their appreciation to Bernard Sagik, Vice President for Academic Affairs at Drexel University, for making it all possible. We would also like to thank Joan McCord, of Drexel's Department of Psychology and Sociology, who graciously provided both the data reported here and permission to use it. Finally, we would like to thank our Drexel colleagues, both faculty and staff, for providing us with ideas, materials to publish, and feedback. Thomas Hewett is with the Department of Psychology and Sociology and Donald Perkey is with the Department of Physics and Atmospheric Science, Drexel University, Philadelphia, PA 19104.
}

\section{CREATION OF THE NEWSLETTER}

Early in the project, it became evident that a vehicle was needed for regular communication between the faculty development coordinator, the microcomputer committees, other microcomputer-related functional groups, and the faculty. In addition, faculty members themselves needed a channel for communication with each other regarding the microcomputer project. To help fill these needs, the faculty newsletter, boot, was born; one editor (T.T.H.) was from the Department of Psychology and Sociology and another (D.J.P.) was from the Department of Physics and Atmospheric Science. The newsletter was established to serve as an informal information exchange on the subject of microcomputers among members of the Drexel community.

\section{Purpose of boot}

The major purpose of boot was to provide a forum for open discussion of ideas and dissemination of information relating to the microcomputer project. Unlike the typical newsletter produced by academic computing centers, boot was edited by faculty; most of its pieces were written by faculty; and it was addressed to all members of the university community, not just that subgroup with a prior interest in, or prior record of, computer use. Consequently, although circumstances dictated that the newsletter serve, in part, as a "bulletin board" for announcements, the emphasis in solicited essays and in editorial material was upon more reflective, more critical, or more evaluative content dealing with issues of pedagogy or application, or with the dangers of microcomputer use or abuse.

\section{Format of boot}

There were also some secondary purposes for boot. The self-imposed format-no more than two pages on one sheet of paper, once a week, every working week of the academic year (and monthly during the summer)-was 
deliberately adopted. This format restricted the length of an issue so that it would be easier to read boot when it arrived than to set it aside for later. In addition, it forced a certain degree of brevity and selectivity upon us so that we were not just filling up space. (Also, given the number of times some editorial materials were rewritten to fit the space available, we believe the space limitation helped improve the clarity of written work which appeared in boot.) The publication schedule was chosen to accomplish two ends. It made boot a regular and reliable feature of the landscape, and it forced us to meet deadlines.

Although other options were available, boot was produced on a microcomputer-based word processor, photocopied from a master copy, and circulated through campus mail. It seemed important to demonstrate directly to non-computer users among the faculty that they need not become programmers to be able to make productive use of a personal computer. Also, given the widespread lack of quality courseware for use in a machine-rich environment (Hewett \& Perkey, 1984), it was particularly important to communicate to faculty, both by discussion and by example, the flexibility and utility of such application programs as the word processor and the electronic spreadsheet, both of which were to be available to all faculty and students. Finally, it seemed that doing boot on a microcomputer-based word processor could accomplish a number of more mundane ends-for example, familiarizing readers with reasonably good quality dotmatrix print.

\section{THE FIRST YEAR AND A HALF}

Over the first year and a half of boot's publication, starting in the winter quarter of 1982-83 and running through the summer quarter of 1984,61 issues were published and distributed to over 1,000 faculty and staff of the university. The newsletter published articles from faculty, academic and administrative staff, graduate students, and undergraduate students working as part of the support staff. The major focus of many of these pieces was on providing faculty and staff with information about personal computers and/or their uses and applications.

In addition to a variety of articles, the weekly issue of boot announced and/or described events related to the microcomputer project. For example, very early in the project a Software Review Center was established and equipped with a variety of microcomputers. From the winter of 1983 to the summer of 1984, a wide variety of software and courseware packages were purchased for faculty review. There were faculty development workshops on general-purpose uses of personal computers and on special topics. A process was created whereby faculty could write proposals to the university for a reduction of teaching load to provide courseware development time. A series of "brown-bag" courseware developers' sessions was started, with individuals actively working on courseware development meeting to discuss problems, activities, strategies, and so forth. "Bits and Bytes" training sessions were instituted for those who wanted to use Ap- ple's Development Workshop for writing Macintosh software. A wide range of speakers appeared on campus, sponsored by different departments and by a grant to the university from the Pew Memorial Trust. The Academic Services staff of the Computer Center was greatly expanded. This expansion included creation of an Instructional Support Group to provide assistance to faculty who were developing courseware, a MicroUser Support Group to provide walk-in and telephone hotline consulting services to any member of the Drexel community, and an Equipment Support Group to deal with distribution and maintenance of machines.

Three classes of freshmen now have their computers, and the university is engaged in a large-scale ongoing research project, directed by a senior sociologist. This project will attempt to evaluate the impact of the new microcomputer policy on students, on faculty, and on the institution. A large and growing number of faculty have direct and easy access to a Macintosh through individual purchase, through university-supplied machines for faculty most heavily involved with the instruction of freshmen and sophomores, and/or through specially created university and/or departmental clusters of machines. Special faculty staff training sessions on the Macintosh and on the use of word processors, spreadsheets, and programming languages are conducted regularly.

Along with announcements concerning the above developments, boot also contained regular listings of new software and courseware available for faculty review in the Software Review Center, an occasional pun or two, a three-part series on income taxes and personal computers, and many glossary terms, some accompanying articles and some used as supplementary material. After distribution of the Macintoshes, boot published tips of the week concerning use of the machine and its associated software, as well as an announcement of the installation of videoprojection units in several classrooms and a discussion on how to use them effectively in conducting classroom demonstrations.

\section{TOPICS OF boot ARTICLES}

In the summer of 1984, as we approached the end of our tenure as editors, we took some time to see if there had been any coherent pattern to the essays that had appeared in boot. At first we thought the various subjects formed a collage. Upon further analysis, however, we were able to discern a pattern. In selecting and/or soliciting material we had tried to pick subjects which met the information needs expressed by our colleagues, or which were, in and of themselves, informative to a wide spectrum of microcomputer users or potential users. We also tried to reflect some of the concerns and interests voiced by our colleagues as they faced the introduction of the personal computer into their professional and personal lives.

While there were some pieces that did not fit the overall pattern, we found many that were organizable into four major groups: (1) faculty and staff development, 
(2) microcomputer applications, (3) project impact and evaluation, and (4) cautions and precautions.

\section{Faculty and Staff Development}

Within the category of faculty and staff development there were three subgroups of articles that stood out. One set of three articles reported on different training models for enabling faculty and staff to develop computer literacy and experience. One of these articles reported on a 5-week series of faculty development training sessions using the Apple II to introduce word processing, spreadsheet and database applications, the BASIC programming language, and several educational software packages to faculty who enrolled in the hands-on workshops. A second article discussed a series of 2-day orientation workshops offered to introduce university administrators and staff to several brands of micro- and minicomputers. The last article in this set reported on a workshop series for faculty of the College of Business and Administration. This series used the Apple Lisa and focused on preparing participants to be "able to sit in front of Lisa and productively use a number of different software packages." Each of these articles reported success and encouraged others to enroll in such workshops or to offer their own such workshops. Although these particular training sessions were conducted before the arrival of the Macintosh, as one faculty member who attended the faculty development sessions pointed out, it was really not necessary to know which word processor would be available to our students. One could learn how word processors work in general, and then be able to plan ways of using this tool for class and professional activities.

A second set of faculty and staff development articles was intended to provide clear, nontechnical explanations of various components and processes in microcomputers for the benefit of faculty and staff who had little or no computing experience. In addition to the glossary terms already mentioned, these articles included discussions of machine language, binary and hexadecimal number systems, integrated circuits, and computer storage media (i.e., disks, tapes, etc.).

The final set of articles in the faculty and staff development category included reviews of guest speakers who were brought to Drexel either as colloquium speakers or as speakers in a university-wide series of lectures under the general theme of "Education in a Technological World." Each speaker, in his or her own way and at a different level, provided some unique and important insights into how to deal with computers in the educational process, or with some of the implications of using computers in higher education.

\section{Microcomputer Applications}

From the third issue of boot, when we published a paragraph on using an electronic spreadsheet simulator to teach physics, we made an effort to find articles focusing on some useful characteristic of the personal computer as a pedagogical tool. Consequently, there were a number of articles illustrating a variety of apparently special-purpose uses that were actually generalizable beyond the particular context illustrated in the article. These articles described actual or planned uses of the microcomputer in courses as diverse as economics and business, biology, physics, history and politics, biomedical engineering, and English as a second language.

For example, a history professor suggested a method whereby the graphics capability of the Macintosh could be used to allow a student to "participate" in the "redrawing of the map of Europe" which took place after the Treaty of Versailles. A physics professor described how a machine the size of a modern personal computer might be used to allow students to do computational problems in physics which were done 25 or 30 years ago on much larger and less powerful machines. A confirmed vegetarian described his development of a program to calculate the complete protein value of various sources of amino acids present in different combinations of foods. He also illustrated how the program could be used as an aid in health-care delivery to patients with special dietary protein requirements. (In addition, we published his recipe for "computer bread." This recipe, worked out using the program, optimizes the body availability of complete protein from the various incomplete protein sources combined in the recipe. It also makes a loaf that tastes good.)

Along with these application articles, there were a set of articles dealing with word processing and a set dealing with database searching. The articles on word processing described faculty reactions to using or anticipating the use of word processors, described an instructional usage of word processors in teaching technical writing, and explored some possible effects of the use of a word processor on the process of writing. The articles on database searching described the availability of data bases, the introduction of student database searching as a component of the freshman humanities sequence, and some of the effects of database searching on the selection and development of term paper assignments.

Although some people believe that the importance of word processing, both as a personal and as a pedagogical tool, has been overstated or overemphasized, it is clear that a personal word processor can have great impact on the way we think, work, teach, and learn. To refer to it as "just a word processor" seems somehow inappropriate for such a powerful tool. Both the electronic spreadsheet simulator and on-line bibliographic database searching also promise to be as powerful pedagogical tools as they are professional tools.

\section{Project Impact and Evaluation}

The third general category of articles contained only three pieces. One, by the director of graduate placement, described the initial reactions to the microcomputer policy of potential employers of Drexel students. The second, by two of Drexel's cooperative education placement coordinators, described some reactions of a sample of employers of Drexel's co-op students. In general, the reac- 
tions of both potential and actual employers were either cautious support for the idea of the microcomputer policy or casual acceptance of what seemed to be a reasonable idea. The third paper was a report about the early stages of a large-scale, ongoing attempt to evaluate the impact of the personal computer policy on students, faculty, and the institution itself.

These articles reflected the idea that required student access to a personal computer cannot, and should not, be considered only in terms of short-range impact and the day-to-day problems of developing courses and instructional materials. There are also long-term, far-reaching implications of the microcomputer policy, which will only become clear with time. The microcomputer policy is a social, as well as educational, experiment, and needs to be viewed in that context.

\section{Cautions and Precautions}

The final general category of articles dealt with cautions and precautions. One obvious major problem with the introduction of personal computers onto a university campus, especially for an urban university, involves the physical security of the hardware. The director of safety and security at Drexel contributed a piece for boot which focused on that problem. However, this article emphasized the difficulty of recovering not only the hardware, but also the software and data that typically disappear along with the hardware. Other articles dealt with different issues-computer crime, expecting too much from the computer, and using the computer whether it is needed or not. The piece on computer crime was published just a week or so before a representative of the Philadelphia district attorney's office gave a talk on campus about computer crime. The piece on expecting too much from the computer raised cautions about expecting students' writing to improve just because each would have a word processor. The most intriguing of these pieces, however, was one that focused on the seductive danger that lies in allowing the power of the computer to become a substitute for the power of thought.

\section{boot EVALUATION DATA}

There are a variety of reasons for believing that the production of a faculty newsletter was a worthwhile activity during the inital period of faculty development efforts at Drexel. These include a strong belief in the value of effective communication of information in helping faculty to cope with the introduction of a new technology in their professional and personal lives; unsystematically collected feedback from various colleagues, and the personal ego investment involved in having worked hard in an attempt to do a good job. None of these, however, provide as firm a basis for evaluation of worth as do data collected in a relatively systematic fashion and in a context in which personal offense can be neither given nor taken. Fortunately, such data are available.

\section{Faculty Survey}

As part of Drexel University's microcomputer project, the university has enlisted the talents of Joan McCord, a sociologist with extensive experience in doing longitudinal research and social program impact evaluation. The focus of the study is to understand the consequences of the microcomputer policy for students, faculty, and the institution itself. As part of this study, faculty members have been asked to complete two questionnaires. The second of these questionnaires was circulated to the faculty in April 1984. This was about a month after the first freshman class to be impacted by the microcomputer policy had received their machines. Significant numbers of faculty had either purchased a machine or been allocated one by the university in connection with their teaching duties. This was also well over a year after the publication of boot began.

\section{Questionnaire and Responses}

Included in the questionnaire was a listing of 22 different activities or facilities which had been a part of the university's faculty development efforts at one time or another, beginning in the winter term of 1982-1983. Faculty were asked to rate each item on a 5-point scale. The response categories were "clearly worthwhile," "of some benefit," "no opinion," "'a waste of time," and "harmful." Eighty-five percent of the 337 members of the full-time, regular faculty responded to the second questionnaire. Although not all of these faculty rated the different approaches to increasing faculty interest and competence in computing, 253 did respond to this section of the questionnaire. Presented in Table 1 is a list of the various faculty development activities and facilities created

Table 1

Percentages of Survey Respondents Indicating the Activity Was "Clearly Worthwhile"

Activity Percentage

Released time for course[ware] development 67

Publication of boot 60

[Room full of machines for faculty use] 59

Software Review Center 53

Specialized introductory sessions $\quad 47$

Hotline for Mac[intosh] questions $\quad 44$

Individual tutoring by colleagues $\quad 43$

General microcomputer seminars $\quad 42$

Lecture/demonstraton of uses in field 40

Workshops by specialists $\quad 38$

Individual tutoring by [staff] professionals 36

Lecture/demonstration of computer tools 34

Availability of Lisa [computers] 31

Taped instructions $\quad 29$

Single-session seminars by colleagues $\quad 26$

[Courseware] developers' sessions 25

Series of guest speakers $\quad 24$

Single-session seminars by professionals* 20

Individual tutoring of faculty by students $\quad 17$

Bits and Bytes [technical] seminars 15

Speakers who came to Drexel 15

Single-session seminars by students

8

*Nonstaff professionals who speciaize in training for computer use. 
by the university. The list is ordered by the percentage of respondents who rated the activity or facility as being "clearly worthwhile." These percentages are reported in the second column of the table.

From these data it can be seen that four things were considered to be "clearly worthwhile" by more than half of the respondents. The thing considered worthwhile by the largest number of respondents was released time for course[ware] development work (67\%). Next on the list were the publication of boot $(60 \%)$, a room full of machines for faculty access (59\%), and the Software Review Center (53\%). (The Software Review Center is a library-type facility containing a variety of machines and a wide range of software and courseware for these machines.)

\section{Conclusions and Discussion}

Most Drexel faculty felt the publication of boot was clearly worthwhile. Given that the responses were not independent of each other, we have not attempted to make any statistical comparisons between the various activities and facilities on this list. Also, there is a further complication which led us to avoid attempting statistical comparisons. In part, the exposure of each faculty member to many of these activities and facilities was on the basis of selfselection. Consequently, the fact that only $15 \%$ of the respondents found the "Bits and Bytes" seminars to be worthwhile is more likely to be an indicator of the number of faculty who had an interest in learning about the Lisa-Macintosh cross-development workshop for writing their own applications programs than it is to be an indicator of the worth of these seminars. It is this self-selection factor, however, that reinforces our conviction that the publication of boot was indeed a worthwhile activity. Although nobody had to read boot, and some faculty told us that they never did, a large number of our colleagues clearly found it worth their time to do so.

\section{CONCLUSION}

In retrospect, we believe that boot, as one part of the faculty development effort, served some important functions for the Drexel University community. One of these functions was informational/educational. The kinds of content we would recommend for a newsletter produced in similar circumstances are illustrated above in the descriptions of the materials we actually published. Many of the articles and materials focused on providing faculty and staff with information about personal computers and/or their uses and applications. However, unlike newsletters produced by academic computing centers, boot was edited by faculty; most of it was written by faculty, focus- ing on some useful characteristic of personal computers as a pedagogical tool; and it was addressed to all members of the university community, not just that subgroup with prior interest in, or prior record of, computer use. Thus, the newsletter was more than just a mechanism for dissemination of information relating to the microcomputer project. It also served to provide faculty members a channel for communication with each other and a forum for discussion of ideas.

Another, and perhaps more important, function of boot was helping to provide many faculty and staff with a sense of community, of continuity, and of ongoing activity. Several pieces published in boot reflected faculty concerns, or addressed specific information needs expressed by our colleagues as they faced the introduction of the personal computer into their professional and personal lives. Furthermore, boot provided a way to illustrate, both by discussion and by example, the flexibility and utility of such important application programs as the word processor and the electronic spreadsheet simulator. It also provided a way to communicate to non-computer users among the faculty, both by discussion and by example, that they did not need to become programmers to be able to make productive use of a personal computer. Finally, the regular appearance of boot, and the sense of ongoing activity it provided, seems to have been especially important to some faculty during the occasional periods of uncertainty and/or waiting for things to happen which were an unavoidable part of the early stages of the implementation of a new university-wide policy.

Drexel has begun an exciting experiment in integrating modern computer technology into the way faculty and students teach and learn. The success or failure of different aspects of this project will not be determined for several years to come. There is, however, no doubt that the impact of this experiment has changed the face of Drexel University. For one thing, it has weakened many of the artificial boundaries between colleges and departments that had evolved over many years. It has also created an atmosphere encouraging far greater communication and cross-fertilization of educational goals and methods. Finally, a new sense of excitement and vitality has been kindled within the Drexel community.

\section{REFERENCES}

Hewett, T. T., \& Perkey, D. J. (1984). The mythical "mountain" of software. Collegiate Microcomputer, 2, 207-210.

Smith, A. L., Hewett, T. T., Perkey, D. J., Russell, R. N., Burton, J. S., Eisenstein, B. A., Herr, A. J., Carmone, F. J., JR., Farouk, B., Gordon, W. J., \& Strong, G. W. (1984). On selecting a microcomputer for 1800 freshmen at Drexel. Collegiate Microcomputer, 2, 107-112. 